\title{
The role of FOZO-PREMA in kimberlite genesis
}

\author{
ANDREA GIULIANI ${ }^{1,2, *}$ \\ MATTHEW G. JACKSON ${ }^{3}$, ANGUS FITZPAYNE ${ }^{1}$
}

${ }^{1}$ Department of Earth Sciences, ETH Zurich

(*andrea.giuliani@erdw.ethz.ch)

${ }^{2}$ School of Earth Sciences, The University of Melbourne

${ }^{3}$ Department of Earth Sciences, University of California,

Santa Barbara

FOZO-PREMA is an ubiquitous component of oceanic basalts and was originally defined by the convergence of Sr$\mathrm{Nd}-\mathrm{Pb}$ isotope trends of ocean island basalts (OIBs) from individual island-seamount chains [1]. FOZO-PREMA is also widespread in juvenile continental magmas, which argue for a global relevance of this component irrespective of the tectonic settings. Early studies proposed that FOZO-PREMA could be a physically discrete reservoir derived from depletion of primitive mantle based on the combination of geochemically depleted ${ }^{143} \mathrm{Nd} /{ }^{144} \mathrm{Nd}$ combined with elevated ${ }^{3} \mathrm{He} /{ }^{4} \mathrm{He}$ ratios [2]. Conversely, later models showed that isotopic compositions spanning the FOZO-PREMA field can be obtained by mixing recycled oceanic crust and mantle material previously depleted by crust extraction [3].

Kimberlites can provide a new perspective on this debate because a recent study of the $\mathrm{Nd}$ and $\mathrm{Hf}$ isotope compositions of kimberlite through time shows that these magmas sample a deep, long-lived, homogeneous reservoir, which might contain remnants of early Earth differentiation processes [4]. We critically review the $\mathrm{Sr}, \mathrm{Nd}$ and $\mathrm{Hf}$ isotope compositions of kimberlites that were emplaced from $\sim 2.1 \mathrm{Ga}$. After screening kimberlite isotopic data for the effects of lithospheric contamination and secondary alteration, we show that kimberlites through time have been derived from a mantle source with FOZO-PREMA composition. This observation makes it unlikely that FOZO-PREMA derives from continuous mixing of depleted and recycled components because the composition of subducted lithologies, pressure and temperature conditions in subduction zones, and temperature and oxygen fugacity conditions of the convective mantle have changed throughout Earth history. We therefore conclude that FOZO-PREMA is a long-lived component of Earth's mantle, which must have existed for at least the last $2.1 \mathrm{Ga}$, the wider implications of which will be discussed.

[1] Zindler \& Hart. Ann Rev Earth Planet Sci 1986, 14: 493571. [2] Hart et al. Science 1992, 256: 517. [3] Stracke et al. G-cube 2005, 6: Q05007. [4] Woodhead et al. Nature 2019, 573: 578-581. 